archives

of thermodynamics

Vol. 36(2015), No. 1, 139-156

DOI: $10.1515 /$ aoter-2015-0010

\title{
Convective heat transfer for fluids passing through aluminum foams
}

\author{
ROMAN DYGA ${ }^{1}$ \\ LEON TRONIEWSKI
}

Opole University of Technology, Department of Chemical and Process

Engineering, Mikołajczyka 5, 45-271 Opole, Poland

\begin{abstract}
This paper analyses the experimental findings within heat transfer when heating up air, water and oil streams which are passed through a duct with internal structural packing elements in the form of metal foams. Three types of aluminum foams with different cell sizes, porosity specifications and thermal conductivities were used in the study. The test data were collected and they made it possible to establish the effect of the foam geometry, properties of fluids and flow hydrodynamic conditions on the convective heat transfer process from the heating surface to the fluid flowing by (wetting) that surface. The foam was found to be involved in heat transfer to a limited extent only. Heat is predominantly transferred directly from the duct wall to a fluid, and intensity of convective heat transfer is controlled by the wall effects. The influence of foam structural parameters, like cell size and/or porosity, becomes more clearly apparent under laminar flow conditions.
\end{abstract}

Keywords: Aluminum foam; Geometric structure of foam; Convective heat transfer

\section{Nomenclature}

$c \quad-\quad$ specific heat, $\mathrm{J} /(\mathrm{kg} \mathrm{K})$

$d \quad-\quad$ diameter, $\mathrm{W} /(\mathrm{m} \mathrm{K})$

$d_{h} \quad-\quad$ hydraulic diameter, $\mathrm{W} /(\mathrm{m} \mathrm{K})$

$F_{b} \quad-$ heat exchange surface, $\mathrm{m}^{2}$

$\dot{G} \quad-\quad$ mass flux, $\mathrm{kg} / \mathrm{s}$

\footnotetext{
${ }^{1}$ Corresponding Autor: E-mail: r.dyga@po.opole.pl
} 


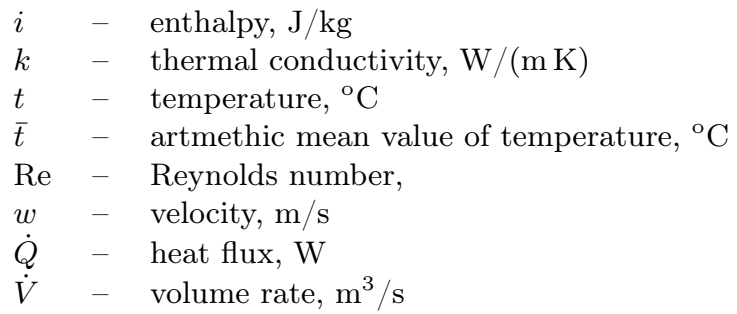

\section{Greek symbols}

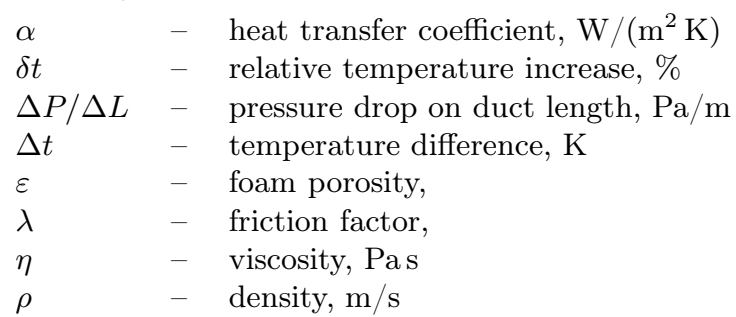

\section{Subscripts}

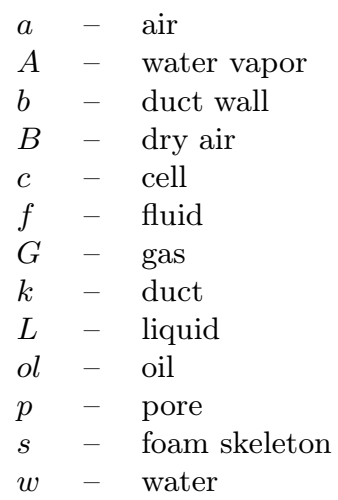

\section{Introduction}

One of the methods used to improve operational performance of the industrial equipment is to employ various structural packing types to multiply the surface which is available for heat/mass transfer. Specific cellular materials, like open-cell metal foams, are recently more and more often used for the purpose of materials packing. The reference papers [1-3] report the use of foamed structures among others in the design of compact heat exchangers, heat accumulators and regenerators as well as chemical catalytic reactors. The foamed materials attract the increasing interest because of their geometric structures which are favorable from the viewpoint of flow 
hydrodynamics. The spatial arrangement of the metal skeleton forms relatively large and empty cells - polyhedral bodies which adhere to each other. Those structures provide very high porosity to foamed materials, usually over $90 \%$. Additionally, the sizes and the number of 'windows' between individual cells are sufficiently high to enable a relatively unobstructed flow of fluids through the cellular space. That reduces the loss of pressure and hence the energy required to pass the fluid through that structure.

In case of heat transfer processes, a respectively high thermal conductivity value for metallic foams (in relation to porosity) also needs to be considered. Moreover, the skeleton structure is continuous which eliminates additional thermal resistance which appears at the contact points of individual structural elements of other in other packing types and/or sintered metal beds.

The process application of open-cell metal foams is to a large extent only at the stage of basic research and implementation at present, despite potentially extensive possibilities of commercial utilization. Before metal foams can be generally commercialized in the continuous flow process equipment, it is necessary to learn more thoroughly the thermal and hydrodynamic phenomena which are concomitant with the flow of fluids through the cellular space. One can find many inaccurate or even conflicting statements in the reports at present within the effects of metallic foams on heat transfer in the continuous flow equipment. The authors who present their research papers in that area usually report that the convective heat transfer coefficient clearly increases, by the factor of $2-4$, in relation to the classical-type tubular and/or plate heat exchangers with no elements which would intensify the heat transfer process. In the opinions presented by Boomsma et al. [4] and Wang et al. [5], the intensity of heat transfer can be even over 10 times better. According to the authors of [4], the heat exchange efficiency can be by as much as $50 \%$ better than for plate heat exchangers, irrespective of the increased demand for energy to pump the fluids. The heat exchangers in the construction of which metallic foams have been used can also offer a very favorable ratio of the thermal flux to the weight and volume of the exchanger. As specified by Ozmat et al. [6], it is possible to reach the heat flux density up to $5000 \mathrm{~kW} / \mathrm{m}^{2}$ of the surface to be cooled down. On the other hand, the effects of structural parameters of metal foams on heat transfer are not so unanimous. The opinions presented in literature on the importance of porosity are generally similar. Porosity of foams varies in a relatively narrow span, and hence its changes do not affect considerably 
the flow turbulence level which could result in changes in the convective heat transfer coefficient. At lowering porosity, the specific surface area of a foam (its heat exchange area) increases and so does the heat flux which is transferred by thermal conduction. In accordance with the data published among the others by the authors of [7-9], the convective heat transfer coefficient increases for higher pore packing densities (number of pores per unit area). When the porosity is kept constant, specific surface area of a foam increases then. The research findings presented in [10-12], however, are indicative of an opposite relation, i.e., heat transfer intensity increases for lower pore packing densities. That fact may be accounted for by a more free flow of fluids in large cells of foams. Then, the authors of [13] and [14] present the opinion that a change in the pore packing density within 5-40 PPI (pore per inch) does not affect the heat transfer conditions at all.

Only one fluid (air or water) was used so far by most researchers who studied heat transfer when a fluid is passed through a metal foam. That makes it difficult to provide any generalization in the description of heat transfer mechanisms. In consideration of the aspects as mentioned above, we decided to run our own research program and to aim it at the heat transfer mechanisms which become valid for fluids flowing through aluminum foams, with special attention paid to the effect of hydrodynamic conditions and foam geometric structures on the convective heat transfer process. These works were a continuation of the research carried out with a flow by wire mesh packing [15] and high-alloy steel FeCrAlY [16].

\section{Experimental}

The tests involved three aluminum alloy foams (Fig. 1) - two of them were made of the AlSi7Mg alloy and one of the Al 6101 alloy. Those materials were selected for tests because they are generally used in thermal engineering. All the foams had similar geometric cellular skeletons and similar porosity specifications. However, they had different cell sizes and pore sizes. In case of metal foams, the term of 'pore' stands for a 'window' through which two adjacent cells are connected with each other (Fig. 1d). Moreover, thermal conductivity of $\mathrm{Al} 6101$ is better than that for AlSi7Mg. It was necessary to provide similarity of some parameters of test foams to be able to evaluate unanimously the effect of cell size on thermal and flow processes which take place inside that cell. If the structural differences of test foams were too high, it would be hard to provide appropriate interpretations for 

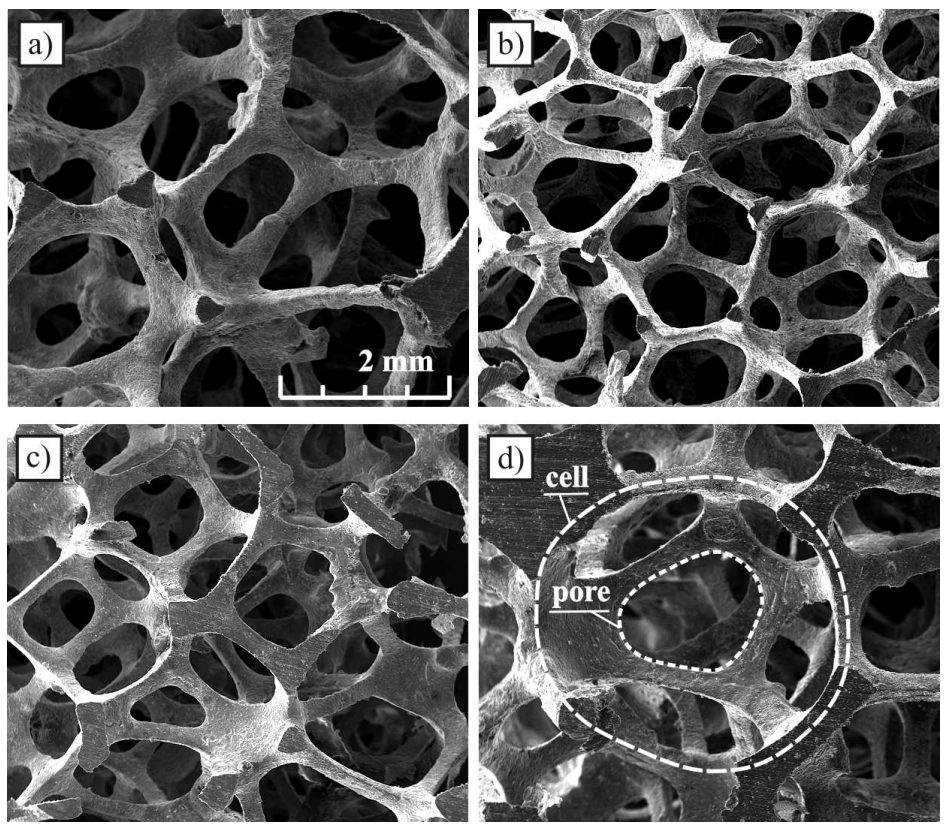

Figure 1: Pictures of foams used in tests: a) AlSi7Mg - 20 PPI , b) AlSi7Mg - 30 PPI, c) Al $6101-40$ PPI, d) cell and pore.

Table 1: Specifications for test foams.

\begin{tabular}{|c|c|c|c|c|}
\hline \multirow[t]{2}{*}{ Denotation (Alloy) } & \multirow{2}{*}{$\begin{array}{c}\text { Porosity } \\
\qquad,--\end{array}$} & \multirow{2}{*}{$\begin{array}{l}\text { Thermal } \\
\text { conductivity } \\
k_{s}, \mathrm{~W} /(\mathrm{m} \mathrm{K})\end{array}$} & \multicolumn{2}{|c|}{ Diameter } \\
\hline & & & $d_{c} \times 10^{-3}, \mathrm{~m}$ & $d_{p} \times 10^{-3}, \mathrm{~m}$ \\
\hline $\begin{array}{l}20 \text { PPI } \\
(\mathrm{AlSi} 7 \mathrm{Mg})\end{array}$ & 0.9336 & 150.4 & 3.452 & 1.094 \\
\hline $\begin{array}{l}30 \text { PPI } \\
(\mathrm{AlSi} 7 \mathrm{Mg})\end{array}$ & 0.9435 & 189.4 & 2.255 & 0.712 \\
\hline $\begin{array}{l}40 \text { PPI } \\
(\mathrm{Al} 6101)\end{array}$ & 0.9292 & 189.4 & 2.386 & 0.824 \\
\hline
\end{tabular}

the findings. The selected foam parameters were presented in Tab. 1.

The pore packing density was taken as the classification parameter for test foams. According to foam producers, that was equal to 20 and 30 PPI in the case of AlSi7Mg and $40 \mathrm{PPI}$ for $\mathrm{Al}$ 6101. The pore size and cell size was each time found graphically from the analysis of the microscopic pictures of foam skeletons. The pictures were taken with the use of a scanning 
electron microscope $(15 \times)$. The average equivalent diameter was assumed as the cell size $d_{c}$. Its value was equal to the diameter of a circle with the area equal to the cell sectional area. The pore equivalent diameter $d_{p}$ was defined in the same way.

Due to the completely open cell structure of foam (no blind and closed cells), the porosity of the foam is defined as the ratio of volume of cellular space to the volume occupied by the foam sample. The volume of cellular space was determined by filling it with liquid. Air, water and machine oil (Velol-9Q) were passed through test foams. From the viewpoint of the subject matter of the research work, the most essential differences in the properties of the fluids were those in their viscosity, density, specific heat and thermal conductivity specifications. These properties, especially dynamic viscosity, varied with temperature changes of fluids $\left(\eta_{o l}=0.1334 t^{0.906}\right)$. For the oil at $20{ }^{\circ} \mathrm{C}$ : dynamic viscosity, $\eta_{o l}=0.0086 \mathrm{~Pa} \mathrm{~s}$, density $\rho_{o l}=$ $859.4 \mathrm{~kg} / \mathrm{m}^{3}$, specific heat $c_{o l}=1848.8 \mathrm{~J} /(\mathrm{kg} \mathrm{K})$, and thermal conductivity $k_{o l}=0.128 \mathrm{~W} /(\mathrm{m} \mathrm{K})$.

\subsection{Test stand and research methods}

The tests were conducted on a stand where a horizontal duct (Fig. 2a) completely packed with aluminum test foams made its primary element (a separate test duct was prepared for each individual foam type). The duct with the total length of $2.61 \mathrm{~m}$ and internal diameter of $0.02 \mathrm{~m}$ had three sections. The central duct section, with the length of $1.27 \mathrm{~m}$, was intended to take measurements: pressure drop, and temperature changes for fluids and for the duct wall. The measurement section could be heated up from outside, over the length of $1.18 \mathrm{~m}$, with the use of a resistance heater which was coiled on the duct. The metal foam was stuck to the duct internal wall in its heated section with the use of a heat-conductive epoxy-aluminum glue. The measurement section was thermally insulated with mineral wool mats (thickness of $0.07 \mathrm{~m}$ ).

Air was fed to the stand from a compressed air system. A multistage impeller pump was used to supply water (demineralized water) and a gear pump was used to supply oil. The flow rates of those fluids were controlled with throttle valves, and they were measured with various types flowmeters. A set of three turbine flowmeters was employed to measure the flow rate of water with the accuracy of $1.5 \%$. The flow rate of oil was measured with the use of a gear flowmeter with the measuring accuracy of $1 \%$. In case of air, because of high pressure drops and changes in air density connected 
with them, two mass flowmeters were used. According to the calibration certificates for those instruments, their maximum measuring error was below $0.3 \%$.

a)

b)
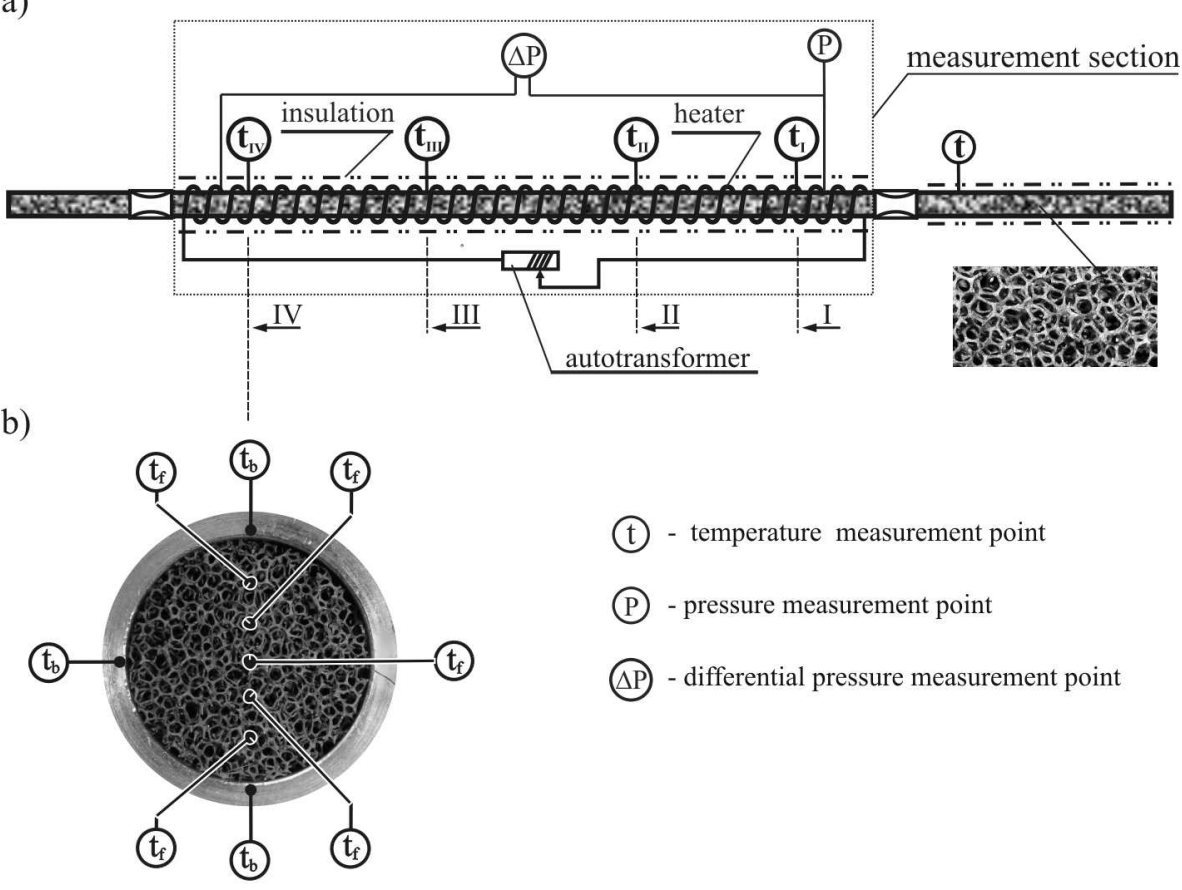

Figure 2: Scheme of test duct: a) Measurement section, $t_{I}, t_{I I}, T_{I I I}, T_{I V}$ - temperature at location I, II, III, IV, respectively, b) arrangement of thermocouples in the duct cross-section, $t_{f}$ - temperature of fluid, $t_{b}$ - duct wall temperature.

The pressure drop was measured along the measurement section as the differential pressure, at the points located $1 \mathrm{~m}$ away from each other. The measurements were taken with a set of five piezoresistive differential pressure instruments with the total measuring range of $0-150 \mathrm{kPa}$. A piezoresistive instrument was also used to measure the positive pressure in the duct (in relation to the surrounding). As declared by the producer, the measuring error for those instrument was below $0.4 \%$.

Temperatures of test fluids and duct wall were measured with type $\mathrm{K}$ thermocouples, with the diameter of $1 \mathrm{~mm}$. Temperatures of fluids were measured immediately downstream of flowmeters as well as in various points along the heated duct section. Temperatures of both the fluid and the duct wall were measured in four places along the duct (locations I, II, III and 
IV in Fig. 2). The measuring points I and IV were located at the distance of $160 \mathrm{~mm}$ from both ends of the heating section, respectively, owing to which temperature measurements could be taken at a stabilized temperature profile. According to the information reported elsewhere, the temperature profile for the horizontal flow through metal foams becomes stabilized at the distance which is equal to 3-4 times the duct transverse size (the length of $160 \mathrm{~mm}$ is eight times higher than the actual duct diameter). Figure $2 \mathrm{~b}$ shows the locations of thermocouples over the duct cross-section. Eight thermocouples were used in each of four measuring points. The measuring tips of five thermocouples were located inside the duct, at different distances from its central line (arranged in the vertical plane). The tips of three thermocouples were located inside the duct wall, at $0.5 \mathrm{~mm}$ from the tube internal surface. The wall temperatures, just alike fluid temperatures, were measured in the lower, central and upper parts of the duct which made it possible to give consideration to the effect of the vertical temperature profile on the average temperature values.

The thermocouples were connected to eight-channel measurement units equipped with the reference temperature stabilization/correction systems. Those units together with a central computer made the data acquisition system. Hence, it was possible to observe and record any current temperature changes at all measuring points at the same time. The temperature measuring system was calibrated beforehand. After calibration, temperature readings from all thermocouples fell within $\pm 0.2 \mathrm{~K}$ in relation to the standard temperature level. The tests were planned in such a way as to obtain similar apparent fluid velocity values, $w_{f}$, for a given fluid and all three metal foams. The apparent velocity should be understood as the average velocity at which a fluid passes through an empty duct (with no metal foam in it)

$$
w_{f}=\dot{V}_{f} \frac{4}{\pi d_{k}^{2}},
$$

where: $\dot{V}_{f}$ - volume rate of fluid, $d_{k}$ - duct diameter.

The measurements were taken for the flow rates which were increasing initially and then decreasing. The heating power was adjusted (by changing the heater supply voltage) at the level which ensured at least a 10-degree growth in the fluid temperature. 


\section{Analysis of research findings}

Since the thermal and hydrodynamic phenomena are directly connected with each other, the flow pattern in the duct was first established before analyzing the findings from thermal tests; the profile of changes in the friction factor, $\lambda$, was utilized for that purpose. The values of the friction factor were found from the Darcy-Weisbach equation and from the pressure drop values $\Delta P / \Delta L$ on duct length as measured:

$$
\lambda_{f}=\left(\frac{\Delta P}{\Delta L}\right)\left(\frac{w_{f}}{\varepsilon}\right)^{-2} \frac{2 d_{h}}{\rho_{f}},
$$

where: $\varepsilon$ - porosity, $\rho_{f}$ - fluids density, $d_{h}$ - hydraulic diameter.

The changes in the friction factor values were analyzed versus the Reynolds number, $\operatorname{Re}_{f}$, which represents the fluid flow conditions and which is defined by

$$
\operatorname{Re}_{f}=\frac{w_{f} d_{h} \rho_{f}}{\varepsilon \eta_{f}},
$$

where $\eta_{t}$ is the fluid viscosity. An equivalent value was assumed for the hydraulic diameter, $d_{h}$; that was calculated from the porosity $\varepsilon$ data and pore diameters, $d_{p}$, in the foam

$$
d_{h}=\frac{\varepsilon d_{p}}{1-\varepsilon}
$$

That approach was found more advantageous (than using one geometric parameter of the foam only) when giving due consideration to the foam structure since porosity and pore diameter parameters are not related to each other. Equation (4) is one of several proposed in the literature for describing the hydraulic diameter in a flow through the metal foam. The authors of the research in this field also use equations, which are taken into account not only porosity, but diameter of the cell, the diameters of the foam skeleton fiber or foam specific surface area.

As can be seen in Fig. 3, the friction factor decreases in the linear way (double-log plot) for increasing $\operatorname{Re}_{f}$ values within low Reynolds numbers which is indicative for a laminar flow regime. The flow pattern is laminar for both liquids and for air when $\mathrm{Re}_{f}$ stays below approx. 150. As regards oil, its flow pattern was laminar over nearly the whole range of $\operatorname{Re}_{f}$ values covered by our experiments. The flow loses its stability at the velocities which correspond to the Reynolds number values above approx. 150. That 


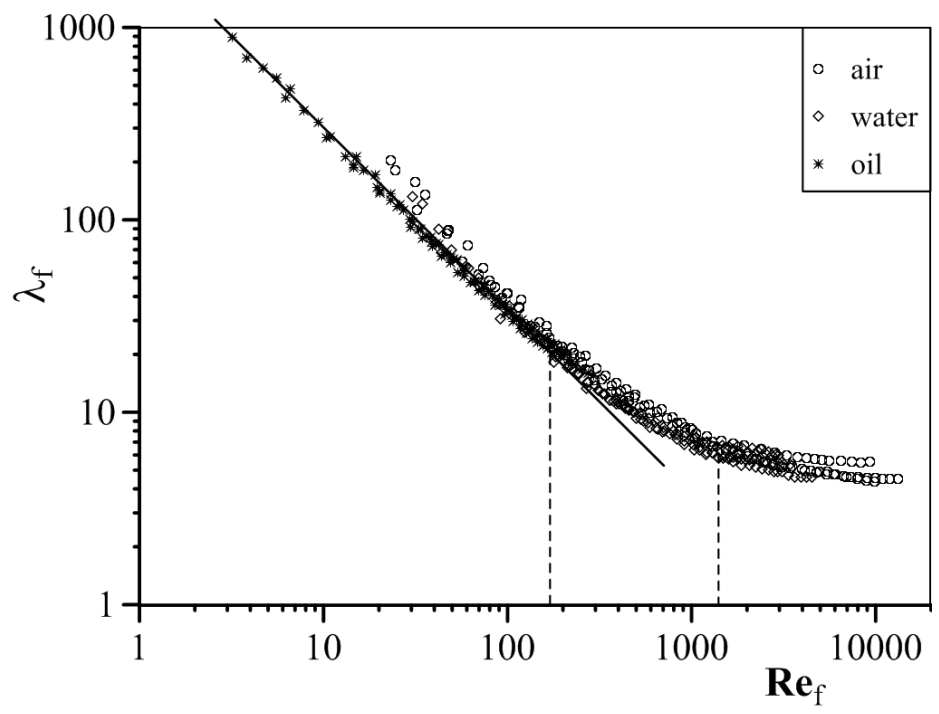

Figure 3: Friction factor versus Reynolds number.

is confirmed by clear deflections of the friction factor values from a straight line profile for $\operatorname{Re}_{f}>150$. It is noticeable at the same time that the slope of the curve for changes in the friction factor is much higher below $\mathrm{Re} \approx 1300$ than for $\operatorname{Re}_{f}>1300$. One may assume that the flow follows the Forchheimer model within $\operatorname{Re}_{f} \approx 150-1300$. According to the present knowledge in the field of the flow through porous bodies, departures from the laminar flow regime in the Forchheimer flow region are quite small. When the fluid velocity is increased, the flow becomes more and more unstable and it greatly shows the characteristics of the turbulent flow $\left(\operatorname{Re}_{f}>1300\right)$. The inertial forces are prevailing over the forces of internal friction, and the flow may be simply dealt with as a fully developed turbulent flow under such conditions. The heat which heats up the duct is transferred to the fluid directly from the duct wall and through the intermediary of the foam skeleton which is fixed to the wall and which is 'washed/wetted' by the fluid. Since it was impossible to measure the temperature of the skeleton surface, the convective heat transfer was analyzed on the basis of the changes in fluid temperatures and duct wall temperatures which were recorded along the flow path, and on the basis of the heat balance for the heated part of the duct.

The heat flux which is necessary to increase the fluid temperature from the level at the entry to the duct (cross-section I in Fig. 2a) to the level at 
the outlet part (cross-section IV) can be calculated as

$$
\dot{Q}_{f}=\dot{G}_{f}\left(i_{f, I V}-i_{f, I}\right),
$$

where $\dot{G}_{f}$ is the mass flux of fluid. The fluid enthalpy values in crosssections I $\left(i_{f, I}\right)$ and IV $\left(i_{f, I V}\right)$ were determined for average fluid temperatures, which were calculated from the read-outs for all thermocouples located in those two measuring points of the duct.

The enthalpy values for liquids $i_{L}$ were found from

$$
i_{L}=c_{L} \bar{t}_{L}, \quad L \equiv w, o l,
$$

where $c_{L}$ is the specific heat of liquid $L$, while subscript $w$ means water and ol means oil.

In case of enthalpy for air, $i_{a}$, additional consideration was given to the atmospheric water vapor content, $Y$, as measured upstream of the measurement duct:

$$
i_{a}=c_{B} \bar{t}_{a}+\left(c_{A} \bar{t}_{a}+r\right) Y,
$$

where $c_{A}, c_{B}$ are the specific heat of water vapor and of dry air, respectively.

The convective heat transfer coefficient $\alpha_{f}$ from the duct wall to the fluid can be established from the calculated heat flux and from the Newton's equation

$$
\alpha_{f}=\frac{\dot{Q}_{f}}{F_{b}\left(\bar{t}_{b}-\bar{t}_{f}\right)} .
$$

The heat exchange surface, $F_{b}$, was assumed to be equal to the internal surface area of the heated section of the measurement duct. Also, the arithmetic mean values for all read-outs from thermocouples located in the duct wall (12 pieces) and from those located inside the duct (20 pieces) were taken as the wall temperature $\bar{t}_{b}$ and fluid temperature $\bar{t}_{f}$, respectively.

Based on experimental points in Fig. 4 one may declare that the convective heat transfer coefficient, $\alpha_{a}$, increases for increasing air velocities. Moreover, the convective heat transfer coefficient, at the same air velocity shows different values for different foams. That is probably conditioned by structural differences in foams and by their thermal conductivities. The highest values for the convective heat transfer coefficient were obtained for the 20 PPI foam while the poorest performance was noted for the 30 PPI foam. Having the specific surface areas for foams in mind, which add to the duct internal surface area as 'components' of the heat exchange areas, the coefficient $\alpha_{a}$ should, in theory, reach higher values for the duct with 30 PPI 
packing since that foam offers a higher specific surface area than that offered by the 20 PPI foam. As the situation observed in experiments was opposite, it suggested that heat was exchanged to a high degree between the duct wall and a fluid stream while the role of foam in heat transfer was limited.

The convective heat transfer coefficient for the 40 PPI foam takes on the intermediate values - between those for the flows through the 20 and 30 PPI foams. The 40 PPI foam is structurally similar to 30 PPI (similar sizes of cells and pores), yet it offers a clearly superior thermal conductivity of its skeleton $k_{s}$ which equals to $189 \mathrm{~W} /(\mathrm{m} \mathrm{K})$ against $k_{s}=150.4 \mathrm{~W} /(\mathrm{mK})$ for 20 PPI and 30 PPI. Having in mind the fact that some part of heat is first transferred through conduction from the duct wall to the foamed structure and only then it can be passed to the fluid stream, different thermal conductivity coefficients for foam skeletons are undoubtedly responsible for higher convective heat transfer coefficients available for flows through the 40 PPI foam as referred to the 30 PPI foam with similar geometry. The research finding within heat conduction in the foam-fluid system were described in more detail in [17].

The situations observed when heating up water and oil were similar to that for air-based tests. The convective heat transfer coefficient value was noted to increase at growing velocities for both those liquids (Figs. 5 and 6). Alike for air heating, the highest values of the convective heat transfer coefficients were available for water and oil flowing through the 20 PPI foam, while the lowest values were obtained for 30 PPI.

The research results also show different profiles of changes in convective heat-transfer coefficient values versus flow velocity for individual fluids. A nearly linear relation of that coefficient versus velocity for air resulted from the fact that the tests for air were conducted at relatively high gas velocities, within the intermediate and turbulent flow region. Liquids were heated up under laminar and intermediate flow conditions.

Some information on the effects of flow conditions and geometrical structures of foams on convective heat transfer is provided by the analysis of temperature differences between the duct wall and the fluid, $\left(\Delta t_{b-f}\right)$, hence of the heat exchange driving force, for the flows through individual foams

$$
\Delta t_{b-f}=\bar{t}_{b}-\bar{t}_{f},
$$

where wall temperature $\bar{t}_{b}$ and fluid temperature $\bar{t}_{f}$ were adopted as in Eq. (8). 


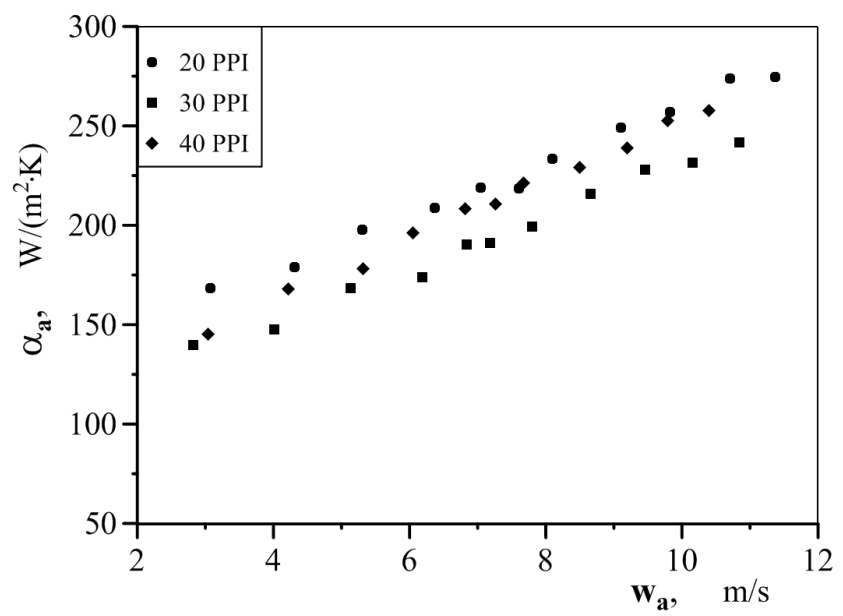

Figure 4: Convective heat transfer coefficient versus air velocity.

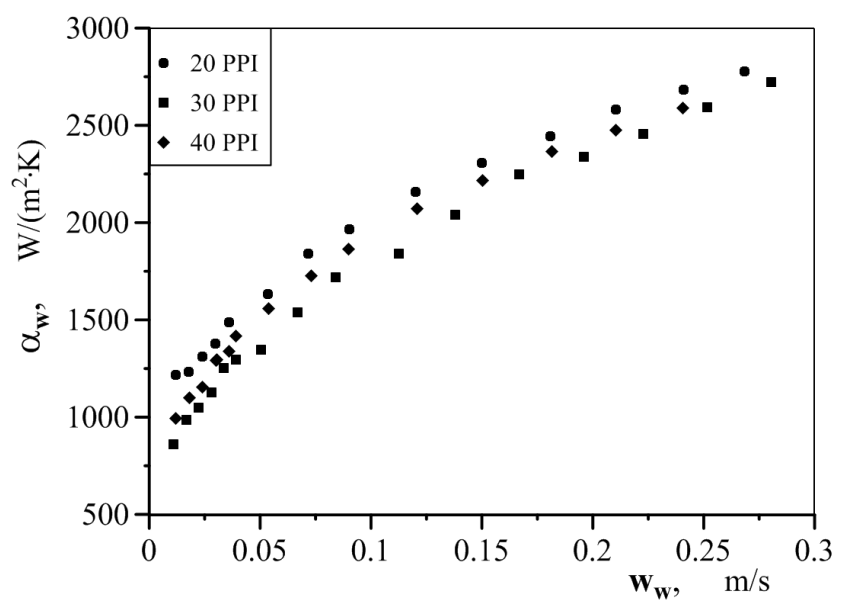

Figure 5: Convective heat transfer coefficient versus water velocity.

Considering the results obtained for water flowing through different packings at the same heating conditions, i.e., at the same heating power and the same flow velocities, the temperature difference $\Delta t_{b-f}$ was found to take on the same values in practice in all three ducts when the water velocity was higher than about $0.12 \mathrm{~m} / \mathrm{s}$ (Fig. 7). The flow becomes turbulent at velocities over $0.12 \mathrm{~m} / \mathrm{s}$. Hence, one can assume that the geometric parameters and foam thermal conductivity have a low effect only on the heat exchange rate under the turbulent flow conditions. The effects of foam 


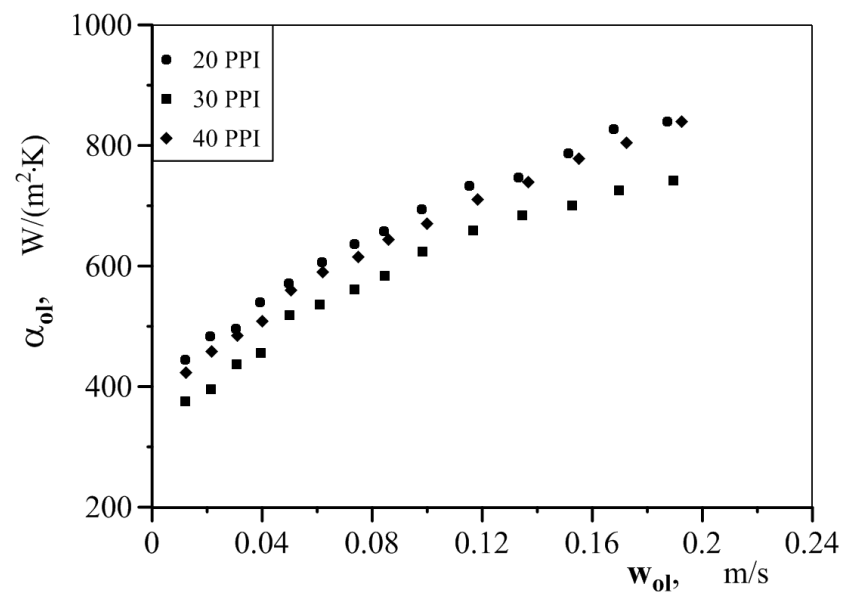

Figure 6: Convective heat transfer coefficient versus oil velocity.

parameters become apparent, however, at lower fluid velocities, under laminar flow conditions and for the Forchheimer flow pattern. As regards the laminar flow regime, heat is less intensively taken away by the fluid from the wall due to fluid stratification. Then, a foam improves the heat exchange performance since it takes heat from the wall through thermal conduction. Within the foams tested, the 20 PPI foam offers the highest gauge ligaments. Hence, thermal resistance for heat transfer from the duct wall to the foam was lowest in that case and the duct wall temperature was lowest for the duct packed with the 20 PPI foam. It is a good thing to mention that heat is exchanged at relatively low temperature differences between the wall and the fluid when the fluid is passed through ducts packed with metal foams. The results of our research (conducted at the earlier stage of our research program [16]) intended to compare convective heat transfer performance for an empty duct and that packed with the alloy steel foam (FeCrAlY) showed clearly that the use of a metal foam lowered the wall temperature so much that heat was exchanged in the packed duct at the value of $\Delta t_{b-f}$ which was 3-5 times lower than that for the empty duct (Fig. 8). At the same time, nearly the same heating effect can be obtained for both ducts as expressed by the relative increase in the fluid temperature $\Delta t_{b-f}$. 


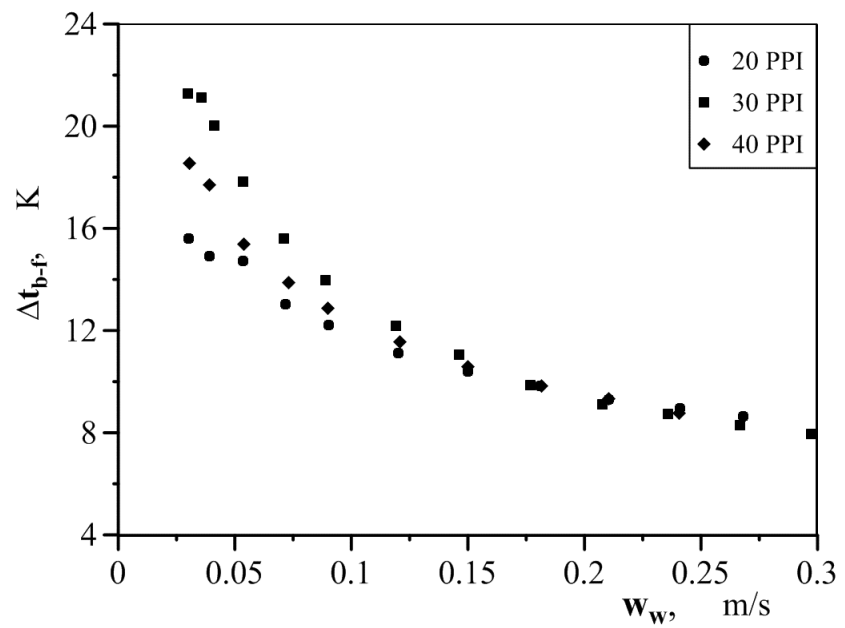

Figure 7: Temperature difference $\Delta t_{b-f}$ for heating up water flowing through aluminum foams.

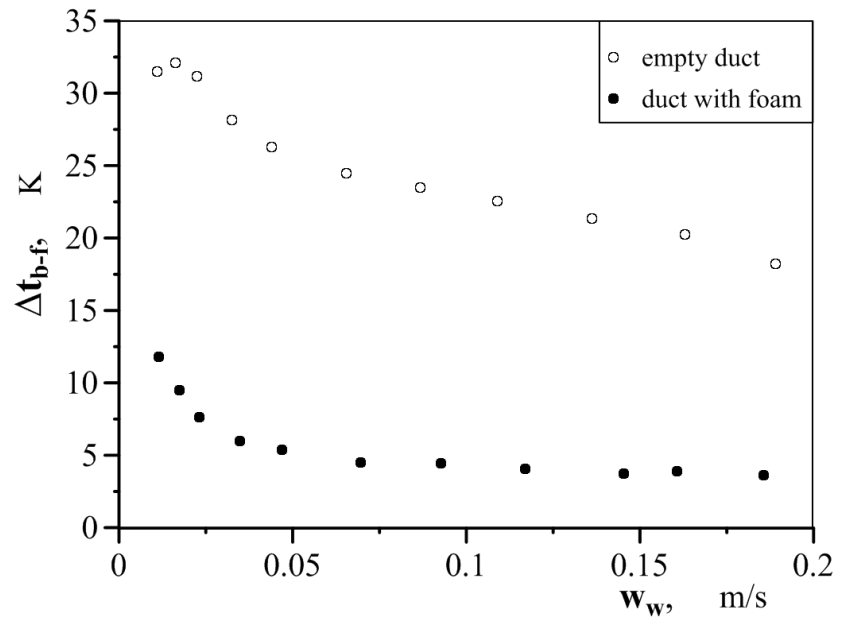

Figure 8: Duct wall temperatures and fluid temperatures for water flowing through an empty duct and through that packed with alloy steel foam (FeCrAlY).

The relative temperature increase was defined as the ratio of the fluid temperature increase over the flow path to the fluid inlet temperature, expressed in per cent

$$
\delta t_{f}=100 \frac{t_{f, I V}-t_{f, I}}{t_{f, I}} .
$$


Defined in this way, that parameter has the physical sense if $t_{f, I V} \geq t_{f, I}$ and $t_{f, I}$. The fact that in both ducts - empty and packed - similar heating effects were obtained for water at the same heating power (Fig. 9) is the evidence of high values of the convective heat transfer coefficient for flows through metal foams (as frequently reported in papers $[4,5,9]$ ) not reflecting the actual heat transfer intensity. Such high values only result from the use of Eq. (8) - that calculation method for the convective heat transfer coefficient is usually employed. The heat exchange area which appears in the denominator of that equation is definitely underestimated since the surface area of the foam skeleton is disregarded.

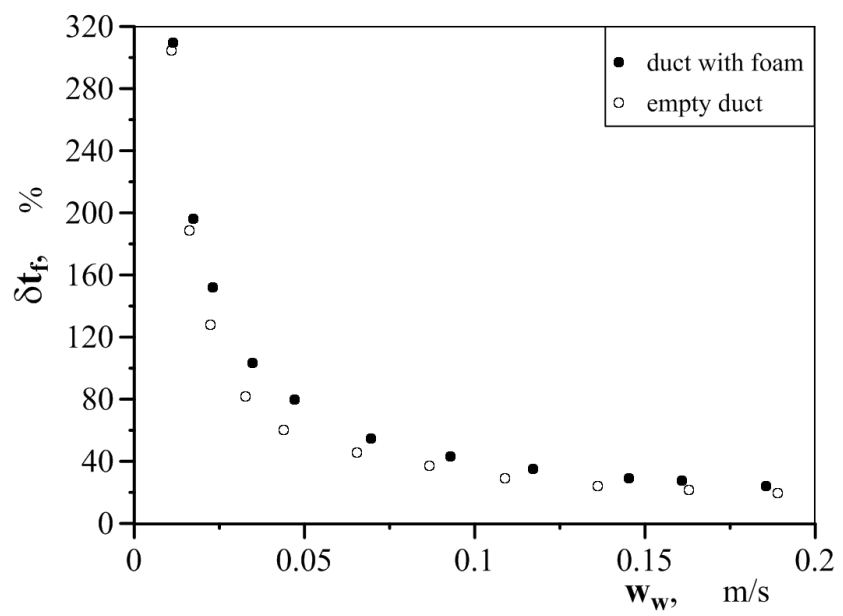

Figure 9: Water temperature increase for water flowing through an empty duct and through that packed with alloy steel foam (FeCrAlY) [16].

\section{Summary}

The experimental findings within heat transfer from a hot duct wall to a fluid which is passed through aluminum foams as packing in the duct show that the fluid removes heat predominantly from the duct wall. Heat is also transferred to the fluid through the foam skeleton but to a much lower degree. The heat exchange performance is controlled mainly by the hydrodynamic flow conditions. The wall effects are of critical importance under the turbulent flow conditions in particular. The effect of the foam structural parameters, like cell size and porosity, becomes more apparent for 
the laminar and intermediate flow conditions. The convective heat transfer coefficient values for all test fluids vary according to the foam type. Those differences, however, are not higher than about $20 \%$.

The profile for the changes in that coefficient is dependent on the flow pattern. For turbulent flow, the convective heat transfer coefficient is more or less proportional to the fluid velocity.

When heat is transferred from the duct wall to the foam through conduction, the wall temperature decreases (in relation to the unpacked duct) which may be of importance from the design viewpoint for the high-temperature process equipment.

Hydrodynamic similarity was shown for the flows through foams with different geometric structures. The fluid flow pattern for the foams may be described with the use of the suitably modified Reynolds number, Eq. (3). That number was defined on the basis of the hydraulic diameter which takes the pore size and foam porosity into consideration. The laminar flow was found to appear for $\operatorname{Re}_{f}$ values below about 150, while for $\operatorname{Re}_{f}>1300$ the flow may be assumed to be turbulent.

Received 10 December 2014

\section{References}

[1] BANHART J.: Manufacture, characterization and application of cellular metals and metal foam. Prog. Mater. Sci. 46(2001), 559-632.

[2] Han X.-H., Wang Q., Park Y.-G., T'Joen C., Sommers A., Jacobi A.: A review of metal foam and metal matrix composites for heat exchangers and heat sink. Heat Transfer Eng. 33(2012), 1-20.

[3] Zнао C.Y.: Review on thermal transport in high porosity cellular metal foams with open cells. Int. J. Heat Mass Tran. 55(2012), 3618-3632.

[4] Boomsma K., Poulikakos D., Zwick F.: Metal foams as compact high performance heat exchangers. Mech. Mater. 35(2003), 1161-1176.

[5] Wang P., LiU D.Y., XU C.: Numerical study of heat transfer enhancement in the receiver tube of direct steam generation with parabolic through by inserting metal foams. Appl. Energ. 102(2013), 449-460.

[6] Ozmat B., Leyda B., Benson B.: Thermal applications of open-cell metal foams. Mater. Manuf. Processes 19(2004), 5, 839-862.

[7] Sertkaya A.A., Altinisik K., Dincer K.: Experimental investigation of thermal performance of aluminum finned heat exchangers and open-cell aluminum foam heat exchangers. Exp. Therm. Fluid Sci. 36(2012), 86-92.

[8] Tzeng S.-C., JengT.-M.: Convective heat transfer in porous channels with 90-deg turned flow. Int. J. Heat Mass Tran. 49(2006), 1452-1461. 
[9] Lu W., Zhao C.Y., Tassou S.A.: Thermal analysis on metal-foam filled heat exchangers. Part I: Metal-foam filled pipes. Int. J. Heat Mass Tran. 49(2006), 27512761.

[10] Bhattacharya A., Mahajan R.L.: Metal foam and finned metal foam heat sinks for electronics cooling in buoyancy-induced convection. J. Electron. Packaging 128(2006), 259-266.

[11] Hutter C., Büchi D., Zuber V., von Rohr Ph. R.: Heat transfer in metal foams and designed porous media. Chem. Eng. Sci. 66(2011), 3806-3814.

[12] XU H.J., QU Z.G., TAO W.Q.: Analytical solution of forced convective heat transfer in tubes partially filled with metallic foam using the two-equation model. Int. J. Heat Mass Tran. 54(2011), 3846-3855.

[13] BAI M.: Numerical evaluation of heat transfer and pressure drop in open-cell foams. MSc thesis, University of Florida, Gainesville 2007.

[14] Magnico P.: Analysis of permeability and effective viscosity by CFD on isotropic and anisotropic metallic Science. Chem. Eng. Sci. 64(2009), 3564-3575.

[15] Dyga R., Witczak S.: Heating of fluid in channel with a wire mesh packing. Arch. Thermodyn. 29(2008), 4, 41-48.

[16] Dyga R., Witczak S.: Heating fluid in a FEC metal-foam filled channel. J. Energy Sci. 1(2012), 2, 51-58.

[17] Dyga R., PŁaczek M.: Heat transfer through metal foamOffluid system. Exp. Thermal Fluid Sci. 65(2015), 1-12. 